\title{
Kathy J. Marshack: Life with a Partner or Spouse with Asperger Syndrome: Going Over the Edge? Practical Steps to Saving You and Your Relationship
}

\author{
Autism Asperger Publishing Co., Shawnee Mission, Kansas, 2009, 176 pp., \\ ISBN: 978-1-934575-47-5, \$19.95 (paper)
}

\section{Oren Shtayermman}

Published online: 13 February 2010

(C) Springer Science+Business Media, LLC 2010

In the majority of professional journals and publications, one will come across vast number of publications aiming to explain, describe and provide some details about potentially effective interventions for individuals diagnosed with Asperger Syndrome (AS). It is infrequent that I come across a publication that focuses solely on the neurotypical (NT) and their challenges living beside an individual who is diagnosed with AS. This 176 pages publication has three different levels of audience: the partners or spouses of individuals diagnosed with $\mathrm{AS}$, children of individuals diagnosed with AS and extended family members and friends who know someone close to them who lives with an individual diagnosed with AS.

Life with a Partner or Spouse with Asperger Syndrome, is a collection of case studies providing a glance into the lives of many women and some men who shared their lives with a person diagnosed with AS. Dr. Marshack presents cases from her private office in which daily emotional struggles of the NT are exposed. The guide presents a diverse selection of issues the NT can be faced with on a regular basis. Examples of the challenges in the guide vary from arranging a wedding, planning a family vacation and how to maintain a sexual relationship with a person diagnosed with AS. Additionally, the author reveals in a sensitive and emotional manner, the encounters and endeavors women (and few men) are faced with while living in a world where spontaneity, empathy and social cues rarely appear.
The reader will instantly notice that each chapter ends with a set of tips and "Lessons Learned" from the case or cases presented. Each chapter consists of vignettes from a therapeutic interaction with clients as well as client's own stories and experiences. For someone like me, who primarily investigate the challenges, experiences and co-morbid issues of adolescents diagnosed with AS, it was quite an insightful moment. The co-morbid issues related to AS as a diagnosis is unfolding through the stories of the clients who decided to begin a therapeutic process at Dr. Marshack's office. The difficulties of living alongside a partner diagnosed with AS are intensified as issues of co-morbidity unfold in the clients' daily living.

The text provides not only some useful didactic information in the form of tips from each of the personal/ professional encounters and stories, but it also provides an opportunity for the reader to self-reflect on individuals they may know or may come to know. The author exposes the painful and emotional struggle the NT individual is carrying in the form of self-blame. The author allows her clients to commence a catharsis of feelings as they relate to their Aspie partner. The book offers a system approach to resolving the unique issues NT/AS families encounter. This is an exceptional book which sheds light on a population often left out of the focus of treatment and in need of further exploration vis-a-vis issues they encounter as well as the possible ways to deal with those.
O. Shtayermman $(\bowtie)$

Department of Interdisciplinary Health Sciences, NYIT School

of Health Professions, Kenneth Riland-Room 354/366,

Old Westbury, NY 11568-8000, USA

e-mail: oshtayer@nyit.edu 